\title{
Inhibition of Dopamine Release Via Presynaptic D2 Receptors: Time Course and Functional Characteristics In Vivo
}

\author{
Marianne Benoit-Marand, ${ }^{1}$ Emiliana Borrelli, ${ }^{2}$ and François Gonon ${ }^{1}$ \\ ${ }^{1}$ Centre National de la Recherche Scientifique Unité Mixte de Recherche 5541, Université Victor Segalen, \\ 33076 Bordeaux, France, and 2Institut de Génétique et Biologie Moléculaire et Cellulaire, 67404 IIlkirch, \\ C. U. de Strasbourg, France
}

\begin{abstract}
Most neurotransmitters inhibit their own release through autoreceptors. However, the physiological functions of these presynaptic inhibitions are still poorly understood, in part because their time course and functional characteristics have not been described in vivo. Dopamine inhibits its own release through D2 autoreceptors. Here, the part played by autoinhibition in the relationship between impulse flow and dopamine release was studied in vivo in real time. Dopamine release was evoked in the striatum of anesthetized mice by electrical stimulation of the medial forebrain bundle and was continuously monitored by amperometry using carbon fiber electrodes. Control experiments performed in mice lacking D2 receptors showed no autoinhibition of dopamine release. In wild-type mice, stimulation at $100 \mathrm{~Hz}$ with two to six pulses linearly inhibited further release, whereas single pulses were inefficient. Dopaminergic neurons exhibit two discharge patterns: single spikes forming a
\end{abstract}

Transmitter release is inhibited at many central synapses by various neuromodulators through presynaptic receptors located on terminal fibers (Nicoll et al., 1990; Thompson et al., 1993; Wu and Saggau, 1997). Autoinhibition is a type of presynaptic inhibition in which neurotransmitters modulate their own release through presynaptic autoreceptors (Starke et al., 1989). Presynaptic inhibition is mainly attributable to the activation of G-protein-coupled receptors, which reduces the presynaptic entry of calcium, a flux necessary for transmitter release (Hille, 1994; Herlitze et al., 1996; Wu and Saggau, 1997). Presynaptic inhibition prevents excessive transmitter release in pathological conditions (Thompson et al., 1993) and might play a major role in adjusting synaptic strength (Isaacson et al., 1993; Wu and Saggau, 1997). However, the part played by central presynaptic inhibition in the relationship between the discharge activity of presynaptic neurons and the release of their neurotransmitter is still poorly understood because major information is lacking: the time course of presynaptic inhibition in vivo.

Kinetics of several forms of heteroregulation and autoregulation have been described in vitro. Durations ranging from 0.5 to 10

\footnotetext{
Received April 24, 2001; revised Sept. 12, 2001; accepted Sept. 17, 2001.

This work was supported by the Centre National de la Recherche Scientifique, the Université Victor Segalen Bordeaux 2, and La Région Aquitaine. We thank M. Jaber, C. Mulle, P. Piazza, D. Sulzer, and R. Warren for their suggestions concerning this manuscript.

Correspondence should be addressed to Dr. F. Gonon, Centre National de la Recherche Scientifique Unité Mixte de Recherche 5541, BP 28, Université Victor Segalen Bordeaux 2, 33076 Bordeaux, France. E-mail: francois.gonon@ umr5541.u-bordeaux2.fr.

Copyright @ 2001 Society for Neuroscience 0270-6474/01/219134-08\$15.00/0
}

tonic activity below $4 \mathrm{~Hz}$ and bursts of two to six action potentials at $15 \mathrm{~Hz}$. Stimulation mimicking one burst (four pulses at $15 \mathrm{~Hz}$ ) promoted extracellular dopamine accumulation and thus inhibited further dopamine release. This autoinhibition was maximal between 150 and $300 \mathrm{msec}$ after stimulation and disappeared within $600 \mathrm{msec}$. This delayed and prolonged time course is not reflected in extracellular DA availability and thus probably attributable to mechanisms downstream from autoreceptor stimulation. Thus, in physiological conditions, autoinhibition has two important roles. First, it contributes to the attenuation of extracellular dopamine during bursts. Second, autoinhibition elicited by one burst transiently attenuates further dopamine release elicited by tonic activity.

Key words: dopamine; release; presynaptic inhibition; D2 receptor; in vivo voltammetry; striatum; mouse

sec have been reported (Davies et al., 1990; Isaacson et al., 1993; Pfrieger et al., 1994; Aroniadou-Anderjaska et al., 2000; Mitchell and Silver, 2000). The most widely documented time course is that of dopamine (DA) autoinhibition in striatum. In vitro studies reported variable durations of autoinhibition from a few seconds (Limberger et al., 1991; Agneter et al., 1994) to > $30 \mathrm{sec}$ (Kennedy et al., 1992) and variable delays of onset ranging from $100 \mathrm{msec}$ (Kennedy et al., 1992) to $750 \mathrm{msec}$ (Mayer et al., 1988; Limberger et al., 1991; Agneter et al., 1994; Cragg and Greenfield, 1997). The only in vivo study reported a delay of onset below $250 \mathrm{msec}$ (Dugast et al., 1997).

DA transmission represents an attractive model to determine the physiological functions of autoinhibition because the discharge activity of dopaminergic neurons has been well described. In rats and mice, they exhibit two discharge patterns: single spikes at a frequency below $4 \mathrm{~Hz}$ and bursts of two to six action potentials at an approximate rate of $15 \mathrm{~Hz}$ (Grace and Bunney, 1984; Sanghera et al., 1984). The present study aimed at describing in vivo the amplitude and time course of DA autoinhibition. In anesthetized mice, DA release was evoked by brief electrical stimulations at $100 \mathrm{~Hz}$ and at frequencies mimicking the discharge patterns of dopaminergic neurons. This release was directly monitored in real time by amperometry combined with carbon fiber electrodes. Autoinhibition of DA release was measured by comparing evoked DA release in wild-type (WT) mice and in mice lacking dopaminergic D2 receptors, because autoreceptors are of the D2 type (Suaud-Chagny et al., 1991; Lhirondel et al., 1998). Dopaminergic cell bodies and dendrites are also equipped with D2 autoreceptors that regulate the discharge ac- 
tivity and, thus, striatal DA release. However, because we monitored the DA overflow evoked by electrical stimulation of dopaminergic axons, we only investigated the function of autoreceptors located on dopaminergic terminals with minimal interference attributable to other autoreceptors. Throughout this article, "DA autoinhibition" refers to autoreceptor functions at terminal level.

\section{MATERIALS AND METHODS}

Experiments were performed in accordance with French (act number 87-848, Ministère de l'Agriculture et de la Forêt) and European Economic Community (act number 86-6091) guidelines for the care of laboratory animals. Mice lacking D2 receptors (D2-/-) were generated as described previously (Baik et al., 1995) and backcrossed onto the C57BL/6 inbred mouse strain. Mice having D2 receptors were mostly of the C57BL/6 strain supplied by Janvier (Le Genest St. Isle, France) and referred to as WT, whereas others $(\mathrm{D} 2+/+)$ were from the same litter as D2 $-/-$ mice. Adult mice (2-4 months old) were anesthetized with urethane $(1.8 \mathrm{gm} / \mathrm{kg}$, i.p.), placed in a stereotaxic frame using a mouse adapter (Stoelting Inc., Kiel, WI), positioned according to the atlas of Franklin and Paxinos (1997), and maintained at $37^{\circ} \mathrm{C}$. In each animal, a concentric bipolar stimulating electrode (SNEX-200; Rhodes Medical Instruments) was implanted in the medial forebrain bundle (MFB) 2.1 $\mathrm{mm}$ posterior to bregma and 1.1 lateral to the medial line. Its depth was adjusted for each experiment so that the DA response in dorsal striatum was maximal. Stimulation pulses $(0.5 \mathrm{msec}, 300 \mu \mathrm{A})$ were applied using an isolated stimulator (DS2; Digitimer, Hertfordshire, UK) triggered by a MacLab/2e system (ADInstruments, Castle Hill, Australia).

The variations of the extracellular DA concentration evoked by electrical stimulations were monitored with a carbon fiber electrode combined with continuous amperometry at $+0.4 \mathrm{~V}$ (Dugast et al., 1994; Benoit-Marand et al., 2000). In each animal, this cylindrical electrode, which has an active surface of a carbon fiber $8 \mu \mathrm{m}$ in diameter and 250 $\mu \mathrm{m}$ long (AGT 10000; SOFICAR, Abidos, France), was implanted in the rostrodorsal striatum $(1.7 \mathrm{~mm}$ lateral, $1.1 \mathrm{~mm}$ anterior to bregma, and $2.75-3.25 \mathrm{~mm}$ below the cortical surface). Transient electrical artifacts were recorded at $0 \mathrm{~V}$ and subtracted (Dugast et al., 1994). The amplitude of the evoked DA overflow was usually expressed in picoamperes or as a percentage. Moreover, after some in vivo experiments, carbon fiber electrodes were calibrated in vitro for DA $(0.2-1 \mu \mathrm{M})$ using a flow injection system $(30 \mu \mathrm{l} / \mathrm{sec})$ with the following perfusion medium (in mM: $137 \mathrm{NaCl}, 2.7 \mathrm{KCl}, 8.1 \mathrm{Na}_{2} \mathrm{HPO}_{4}-2 \mathrm{H}_{2} \mathrm{O}, 1.47 \mathrm{KH}_{2} \mathrm{PO}_{4}$, and 100 ascorbic acid) (Dugast et al., 1994). This calibration allowed us to accurately compare the amplitude of the evoked DA overflow between groups of animals. However, given the differences between in vivo and in vitro conditions, the absolute value of evoked changes in DA concentration, calculated from in vitro calibration, must be considered as a rough estimate.

In experiments described in Figures 1-5, autoreceptors were activated by dopamine whose release was evoked by various types of conditioning stimulation (Sc). Test stimulations S1 and S2 consisted of three pulses at $100 \mathrm{~Hz}$ and were respectively applied $4 \mathrm{sec}$ before Sc and at various time intervals after the end of Sc. In the experiment described in Figure 3, the conditioning stimulation was identical to test stimulations (three pulses at $100 \mathrm{~Hz}$ ). Therefore, the stimulation sequence was simplified and consisted only of two test stimulations, labeled S1 and S2, separated by various time intervals. Each sequence of stimulations (Fig. 3, S1-S2; Figs. $1,2,4,5, S 1-S c-S 2)$ was applied 10 times every $15 \mathrm{sec}$, and the resulting overflow records were averaged (Dugast et al., 1994). In experiments described in Figures 2-5, one parameter was modified (e.g., the number of pulses in Sc) so that each parameter value was applied successively every $15 \mathrm{sec}$ before replication of the same stimulation sequence and off-line averaging. Thus, the consequence of the slow decrease in the amplitude of the evoked DA overflow during prolonged experiments was eliminated.

In all experiments (except that described in Fig. 6), the amplitude of the DA overflow evoked by S2 was expressed as a percentage of the overflow evoked by S1 and was used to measure the inhibition of DA release induced by Sc. These amplitudes were measured from averaged recordings. When the time interval between Sc and S2 was short, the corresponding evoked DA overflow records greatly overlapped. To accurately measure from averaged recordings the amplitude of the overflow evoked by S2, the curve corresponding to a similar overflow evoked by Sc


Figure 1. Effect of haloperidol on DA autoinhibition. Autoinhibition was activated by DA overflow evoked by a conditioning stimulation consisting of six pulses at $15 \mathrm{~Hz}$. The resulting inhibition of DA release was measured by comparing the amplitudes of the DA overflow evoked by test stimulations S1 and S2 (3 pulses at $100 \mathrm{~Hz}$ ) applied $4 \mathrm{sec}$ before Sc and $300 \mathrm{msec}$ after the end of Sc, respectively. Each sequence of three stimulations $(S 1-S c-S 2)$ was applied every $15 \mathrm{sec}$, and a series of 10 successive recordings were averaged. After a control period of $15 \mathrm{~min}$, mice were treated with haloperidol $(0.5 \mathrm{mg} / \mathrm{kg}$, s.c.). The figure shows typical averaged recordings obtained from one WT mouse before and 15 min after haloperidol injection. Because the carbon fiber electrode was calibrated in vitro after in vivo recording, the evoked DA overflow was measured in picoamperes and in DA concentration (nanomolar). In six identical experiments, the amplitude of the DA overflow evoked by S2, expressed in percentage (mean \pm SEM) of the overflow evoked by S1, was $43 \pm 3 \%$ before haloperidol and $85 \pm 4 \%$ after haloperidol. This indicates that DA autoinhibition of S2 by Sc was blocked almost entirely by haloperidol.

(or Fig. 3, S1), but without any overlap and obtained in the same experiment, was subtracted as illustrated in Figure 3. Comparisons of DA autoinhibition in WT mice were performed by a one-way ANOVA having the number of pulses in Sc as within factor, followed by Dunnett's multiple comparison test. Individual comparisons between WT and D2-/- mice were conducted with Mann-Whitney's $U$ test.

\section{RESULTS}

\section{Validation of the experimental protocol}

A typical autoinhibition effect is shown in Figure 1: the DA overflow evoked by the conditioning stimulation inhibited, for a certain time duration, further DA release evoked by the second test stimulation compared with DA release evoked by first test stimulation. The DA overflow evoked in vivo by one pulse is detectable but too small to be reliably quantified in every experiment (Benoit-Marand et al., 2000). Therefore, the test stimulations S1 and S2 consisted of three pulses at $100 \mathrm{~Hz}$. It is likely that autoinhibition was negligible during this brief stimulation (20 msec). Indeed, contrary to DA overflow evoked by prolonged stimulations, the DA overflow evoked by four pulses at $100 \mathrm{~Hz}$ was not affected by pharmacological blockade of autoreceptors (Mayer et al., 1988; Garris et al., 1994).

In our conditions, the amplitude of the DA overflow evoked by S1 was enhanced by systemic haloperidol (Fig. 1). Nevertheless, in agreement with previous studies, this effect is much less pronounced than the enhancing effect of haloperidol on DA overflow 
evoked by a more prolonged stimulation (Fig. $1, S c$ ). Therefore, it is likely that either of two other mechanisms, rather than the onset of fast autoinhibition, might explain the effect of haloperidol on the DA overflow evoked by S1. First, haloperidol blocks the tonic stimulation of autoreceptors induced by the basal extracellular DA concentration (Suaud-Chagny et al., 1991). Second, systemic haloperidol inhibits DA uptake. Indeed, the DA half-life (i.e., the time for $50 \%$ decrease from the maximum) measured from DA overflow evoked by S1 was $73 \pm 4$ msec (mean \pm SEM; $n=6$ ) before haloperidol and $104 \pm 4 \mathrm{msec}$ after haloperidol (Fig. 1). This observation seems in line with the view supported by Cass and Gerhardt (1994) stating that pharmacological blockade of D2 receptors decreases the rate of DA uptake.

Figure 1 clearly shows that blockade of D2 autoreceptors by haloperidol suppressed most DA autoinhibition. Indeed, the amplitude of the DA overflow evoked by S2 was almost entirely restored by haloperidol to that evoked by S1. Moreover, haloperidol heterogenously enhanced the DA overflow evoked by Sc (six pulses at $15 \mathrm{~Hz}$ ): the early phase of the overflow was less affected than the late portion. This suggests that, before treatment, DA released by the first pulses inhibited further release evoked by the following pulses in a train. However, the enhancing effect of haloperidol on the DA overflow evoked by Sc exceeded a $+100 \%$ increase, the maximal effect expected from a pure blockade of DA autoinhibition (Fig. 1). This can be explained, as mentioned above, by the fact that, in addition, haloperidol indirectly inhibits DA clearance. This difficulty inherent to pharmacological blockade of D2 receptors incited us to use mice lacking D2 receptors for control experiments designed to reveal DA autoinhibition.

The 4 sec delay between the first test stimulation and the conditioning stimulation was long enough to prevent any significant influence of the DA released by S1 on the DA overflow evoked by Sc in either WT or D2-/- mice. In fact, when two test stimulations were applied 4 sec apart, DA overflow evoked by the second stimulation did not significantly differ from the first (Fig. 2).

Evoked DA overflow reflects the DA release per pulse (multiplied by the number of pulses) minus DA clearance by reuptake (Garris et al., 1994; Benoit-Marand et al., 2000). Therefore, in comparative studies, the maximal amplitude of the evoked DA overflow provides a relative estimate of the DA release per pulse, providing that the kinetics of DA clearance is not affected. Here, apart from haloperidol effect, this requirement is fulfilled because the kinetics of the DA overflow evoked by test stimulations $\mathrm{S} 1$ and $\mathrm{S} 2$ never differ (see typical recording in Figs. 1-5). Moreover, under our conditions, DA clearance appeared to not be altered by the absence of autoreceptors. Indeed, when the DA overflow was evoked by test stimulations (three pulses at $100 \mathrm{~Hz}$ ), the DA half-life (i.e., the time for $50 \%$ decrease from the maximum) was $79 \pm 3 \mathrm{msec}$ (mean $\pm \mathrm{SEM} ; n=8)$ in WT mice, $75 \pm$ $3 \mathrm{msec}$ in $\mathrm{D} 2+/+$ mice (mean $\pm \mathrm{SEM} ; n=6$ ), and $81 \pm 4 \mathrm{msec}$ in D2 $-/-$ mice (mean $\pm \mathrm{SEM} ; n=7$ ). Our observations are not consistent with those of a previous study showing that DA uptake is decreased in mice lacking D2 receptors (Dickinson et al., 1999). Because in this previous study DA overflow was evoked by local injections of exogenous DA $(400 \mu \mathrm{M})$, differences in experimental conditions might explain this discrepancy. In conclusion, because in our experimental conditions DA reuptake appeared to not be affected by autoinhibition, the maximal amplitude of the DA overflow provided a suitable relative estimate of DA release.

In some experiments, the maximal amplitude of the DA overflow evoked by the first test stimulation was estimated in terms of
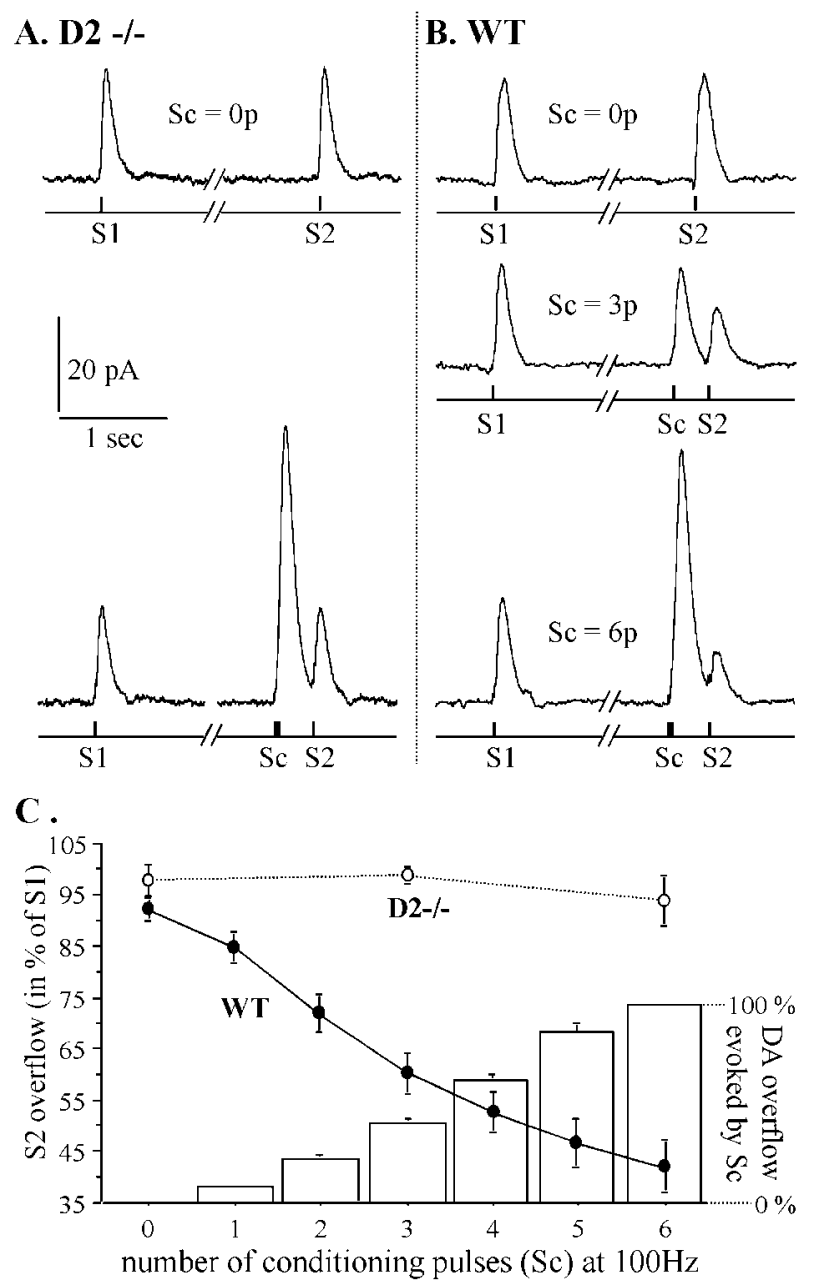

Figure 2. Relationship between the amplitude of the DA overflow evoked by MFB stimulation of one to six pulses at $100 \mathrm{~Hz}$ and the inhibition of DA release. Typical recordings show the DA overflow evoked by three consecutive MFB stimulations in the striatum of one D2-/- mouse $(A)$ and of one WT mouse $(B)$. Inhibition of DA release was measured by comparing the amplitudes of the DA overflow evoked by test stimulations $\mathrm{S} 1$ and S2 (3 pulses at $100 \mathrm{~Hz}$ ). The conditioning stimulation consisted of zero to six pulses at $100 \mathrm{~Hz}$ and was applied $4 \mathrm{sec}$ after S1. The time interval between the end of Sc and S2 was 300 msec. When Sc was 0 , the time interval between S1 and S2 was $4 \mathrm{sec}$. The amplitudes of DA overflow evoked by Sc increased with increasing number of pulses, as exemplified in typical recordings and shown in percentage of the overflow evoked by six pulses at $100 \mathrm{~Hz}$ (mean \pm SEM; 7 WT mice) $(C)$. The amplitude of the DA overflow evoked by $\mathrm{S} 2$ was expressed in percentage (mean \pm SEM) of the overflow evoked by S1 for D2-/mice $(\bigcirc ; n=7)$ and WT mice $(0 ; n=7)$.

extracellular DA concentration by in vitro calibration of the electrode after in vivo recordings. These amplitudes were similar in WT, D2 +/+, and D2-/- mice: they corresponded to $216 \pm 29$ $\mathrm{nM}(n=4), 243 \pm 20 \mathrm{nM}(n=5)$, and $249 \pm 32 \mathrm{nM}(n=7)$ (mean \pm SEM), respectively. This unaltered DA release in D2-/- mice is consistent with a normal striatal tissue level of DA (Kelly et al., 1998) and with no changes in both the expression of mRNA coding for tyrosine hydroxylase (Baik et al., 1995) and dopamine metabolites, suggesting similar rates of DA synthesis (Dickinson et al., 1999). Moreover, in vivo microdialysis studies showed that basal and $\mathrm{K}^{+}$-evoked extracellular DA levels were similar in D2-/- and WT mice (Dickinson et al., 1999). 


\section{Amplitude of autoinhibition}

To investigate the relationship between the level of autoreceptor stimulation and the resulting inhibition of DA release, conditioning stimulations consisting of one to six pulses at $100 \mathrm{~Hz}$ were applied (Fig. 2). This frequency was used because the amplitude of the DA overflow evoked by Sc at $100 \mathrm{~Hz}$ can be simply enhanced by increasing the number of pulses. Indeed, in WT mice, conditioning stimulations at $100 \mathrm{~Hz}$ evoked DA overflow with maximal amplitude that increased linearly with increasing number of pulses (Fig. 2C) (linear regression coefficient, $r^{2}=$ 0.982). In D2-/- mice, conditioning stimulations (three or six pulses) did not further affect DA release evoked by S2, denoting absence of autoinhibition (Fig. $2 A, C$ ). In WT mice, the DA overflow evoked by Sc inhibited further release evoked by S2 (expressed in percentage of S1), and this effect was dependent on the number of pulses in Sc $\left(F_{(6,42)}=26.38 ; p<0.0001\right)$. Indeed, the DA release evoked by $\mathrm{S} 2$ significantly differed $(p<0.001)$ when the conditioning stimulus consisted of two to six pulses compared with the DA release evoked by S2 in the absence of Sc. When Sc consisted of one pulse, the DA release evoked by S2 was slightly decreased, but this effect was not statistically significant $(p>0.05)$. The amplitude of this inhibition correlated with the amplitude of the DA overflow evoked by Sc (Fig. 2C).

\section{Time course of autoinhibition}

To precisely determine the time course of autoinhibition, especially its onset, the conditioning stimulation must be as brief as possible. Figure 2 shows that a conditioning stimulation consisting of only three pulses at $100 \mathrm{~Hz}$ induced a submaximal but robust inhibition of DA release. Therefore, this stimulation was used both as the control test stimulation (S1) and as the conditioning stimulus that inhibited DA release evoked by S2 (Fig. 3). In D2-/- mice, the DA released by S1 never inhibited the DA release evoked by S2. However, at short intervals (100 and 150 msec), the first stimulation facilitated the DA release evoked by $\mathrm{S} 2$. The time course of autoinhibition was studied in two groups of mice having D2 receptors: four D2+/+ mice and $10 \mathrm{WT}$ mice. Because autoinhibition was virtually identical in both groups, the data were pooled. In these mice, the DA released by S1 inhibited the DA release evoked by $\mathrm{S} 2$ at intervals between $\mathrm{S} 1$ and $\mathrm{S} 2$ ranging from 150 to $600 \mathrm{msec}$. At $100 \mathrm{msec}$ interval, autoinhibition was already partly effective because it counteracted the facilitation of DA release observed in D2-/- mice. However, it was not maximal because the difference in the DA overflow evoked by S2 between D2-/- and WT mice was smaller at 100 msec than at $150 \mathrm{msec}$ (Fig. 3C). This difference was statistically significant at intervals of $100 \mathrm{msec}(p<0.01)$ and 150, 200, and $300 \mathrm{msec}(p<0.001)$ but not at $800 \mathrm{msec}(p=0.087)$. From 400 to $800 \mathrm{msec}$, the DA release evoked by $\mathrm{S} 2$ gradually recovered to control value (Fig. 3C).

\section{Autoinhibition induced by stimulations mimicking bursting activity}

Dopaminergic neurons never discharge at $100 \mathrm{~Hz}$. In rodents, their fastest activity occurs in bursts of two to six action potentials at an approximate rate of $15 \mathrm{~Hz}$ (Grace and Bunney, 1984; Sanghera et al., 1984). To investigate the physiological function of autoinhibition, we used conditioning stimulations mimicking bursts and consisting of one to six pulses at $15 \mathrm{~Hz}$. First, we investigated the time course of autoinhibition induced by a conditioning stimulation of four pulses at $15 \mathrm{~Hz}$. Comparison between WT mice and D2-/- mice shows that

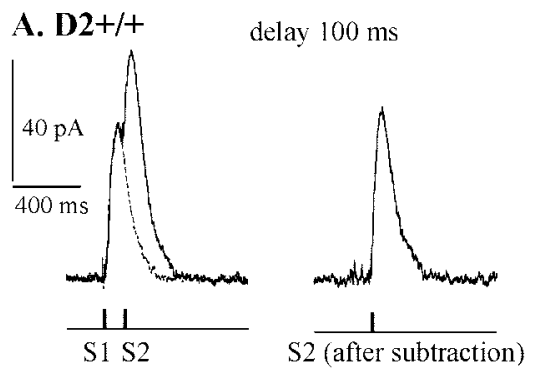

delay $200 \mathrm{~ms}$
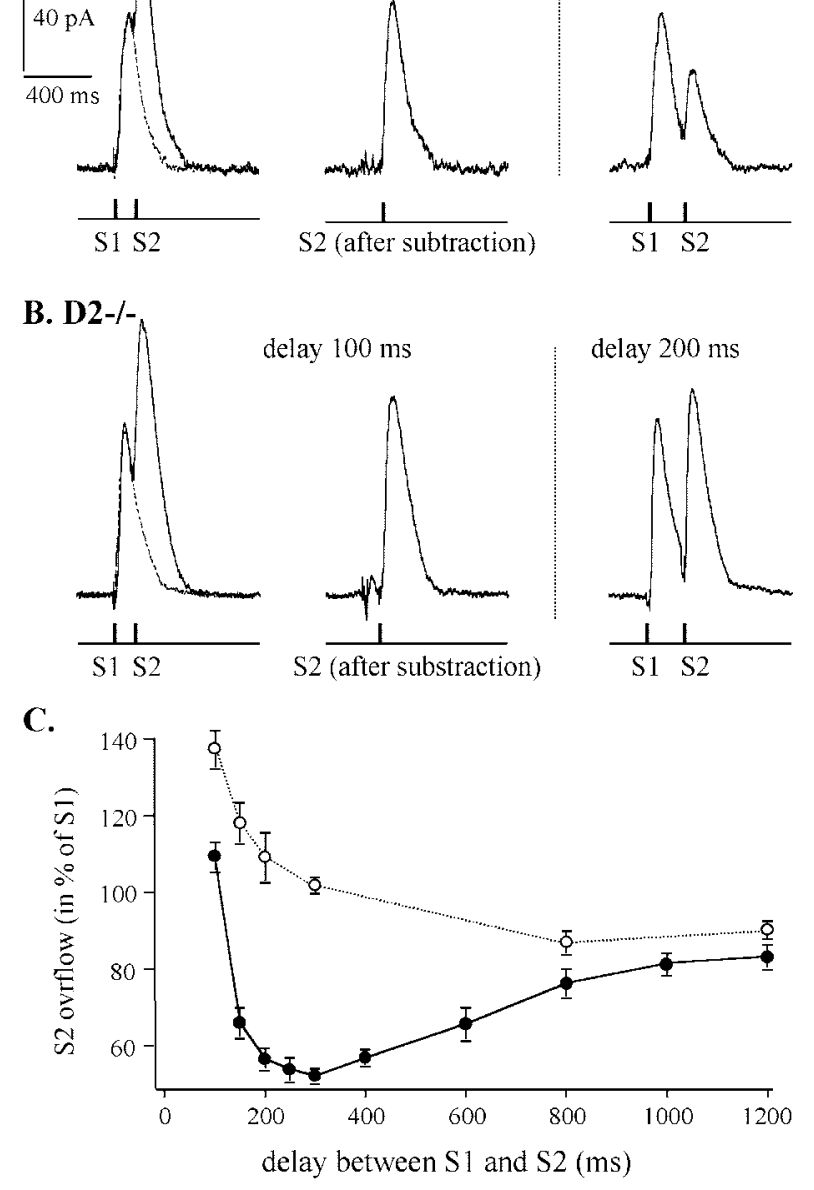

Figure 3. Time course of DA autoinhibition. The first test stimulation (3 pulses at $100 \mathrm{~Hz}$ ) was the conditioning stimulation inducing autoinhibition of DA release evoked by $\mathrm{S} 2$. Time intervals between $\mathrm{S} 1$ and $\mathrm{S} 2$ varied from 100 to $1200 \mathrm{msec}$. Typical recordings show autoinhibition in one $\mathrm{D} 2+/+$ mouse $(A)$ and its absence in one $\mathrm{D} 2-/-$ mouse $(B)$. For short intervals, overflow records evoked by S1 and S2 partly overlapped. To accurately measure the amplitude of the overflow evoked by $\mathrm{S} 2$, the curve corresponding to a similar overflow evoked by S1 but without any overlap and obtained in the same experiment was subtracted. The amplitude of autoinhibition was measured in D2 $-/-$ mice $(\bigcirc ; n=6)$ and in mice having D2 receptors ( 4 D2 $+/+$ mice and $10 \mathrm{WT}$ mice; data pooled) $(C)$. It corresponded to the DA overflow evoked by $\mathrm{S} 2$ expressed in percentage of the overflow evoked by $\mathrm{S} 1$ (mean \pm SEM). At short time intervals (100 and $150 \mathrm{msec}$ ), S1 facilitated DA release evoked by S2, as observed in D2-/- mice $(C)$. In WT mice, this facilitation was counteracted by autoinhibition. Therefore, autoinhibition was already observed at $100 \mathrm{msec}$, reached a plateau from 150 to $300 \mathrm{msec}$, and vanished at 800 msec.

autoinhibition of DA release was maximal between 150 and $300 \mathrm{msec}$ after the end of the conditioning stimulation and vanished after $600 \mathrm{msec}$ (Fig. 4).

The relationship between the number of pulses (from one to six) in a conditioning stimulation at $15 \mathrm{~Hz}$ and the amplitude of autoinhibition at fixed delay is shown in Figure 5. The DA overflow evoked by Sc inhibited additional release evoked by S2 (expressed in percentage of S1), and this effect was dependent on the number of pulses in Sc $\left(F_{(6,70)}=20.68 ; p<0.0001\right)$. More precisely, the amplitude of autoinhibition gradually increased with increasing number of pulses from one to four and then 

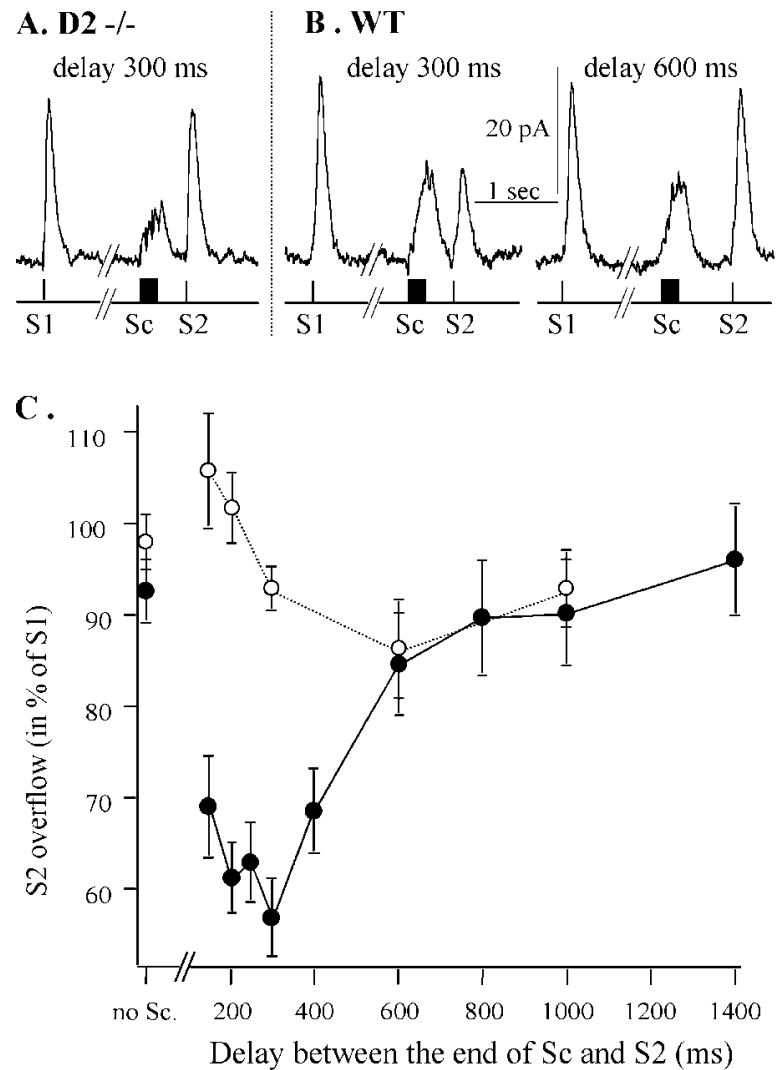

Figure 4. Time course of autoinhibition with a conditioning stimulation of four pulses at $15 \mathrm{~Hz}$. The first test stimulation $(3$ pulses at $100 \mathrm{~Hz}$ ) was applied $4 \mathrm{sec}$ before the conditioning stimulation, and the second test stimulation was applied between 150 and $1400 \mathrm{msec}$ after the end of Sc. In the absence of Sc (no Sc), the delay between S1 and S2 was 4 sec. Typical recordings show the absence of autoinhibition in one D2-/mouse $(A)$ and its presence in one WT mouse $(B)$. The DA overflow evoked by $\mathrm{S} 2$ was expressed in percentage of the overflow evoked by $\mathrm{S} 1$ (mean $\pm \mathrm{SEM}$ ) and reflected the amplitude of autoinhibition in D2-/mice $(\bigcirc ; n=6)$ and in WT mice $(0 ; n=8)(C)$.

reached a plateau with five and six pulses (Fig. 5B). The DA release evoked by S2 significantly differed $(p<0.001)$ when the conditioning stimulation consisted of two to six pulses compared with the DA release evoked by S2 in the absence of Sc. When Sc consisted of one pulse, the DA release evoked by S2 was slightly decreased, but this effect was not statistically significant $(p>$ $0.05)$. In $\mathrm{D} 2-/-$ mice, conditioning stimulations consisting of four or six pulses at $15 \mathrm{~Hz}$ did not affect the DA overflow evoked by $\mathrm{S} 2$ (Fig. $5 A, B$ ).

Comparison between Figures $2 C$ and $4 B$ shows that the relationship between the DA overflow evoked by the conditioning stimulation and the amplitude of autoinhibition is more complex than might be inferred from Figure 2. In fact, conditioning stimulations consisting either of three pulses at $100 \mathrm{~Hz}$ (Figs. 2, 3) or four pulses at $15 \mathrm{~Hz}$ (Figs. 4, 5) induced similar autoinhibition amplitudes, whereas the maximal amplitude of the DA overflow evoked by the former stimulation was approximately twice as high as the overflow evoked by the latter (Fig. 4B, compare DA overflow evoked by S1 to that evoked by Sc). However, when considering the temporal summation of DA overflow (i.e., the area below the curve) rather than its maximal amplitude, the total overflow of DA was more similar (Fig. 4B). This suggests that the maximal extracellular DA level and the duration of exposure to
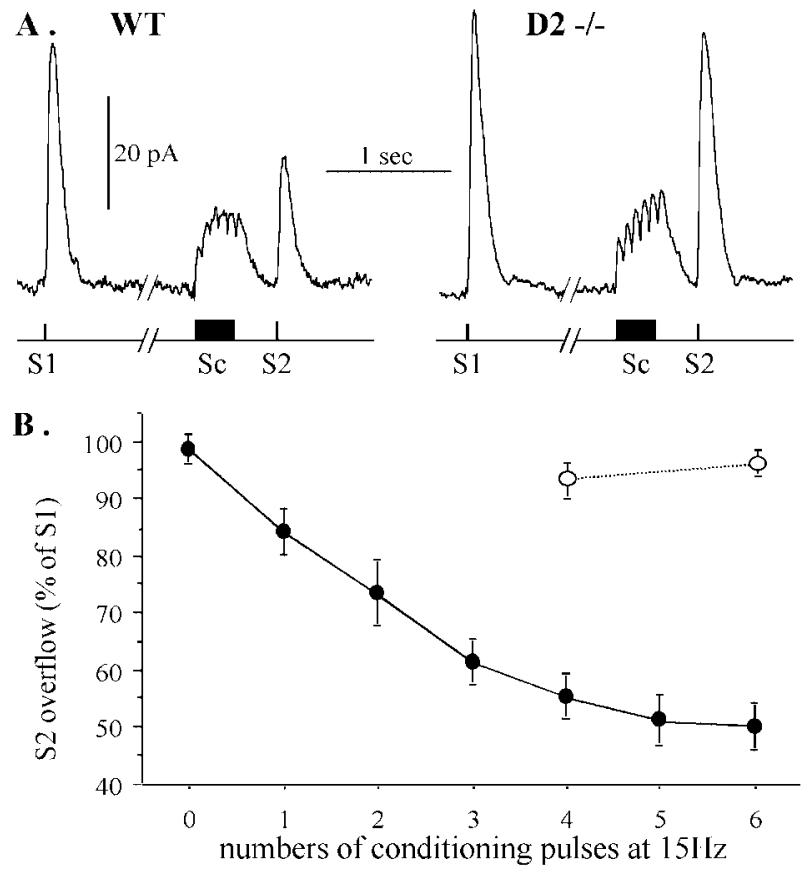

Figure 5. Relationship between the number of pulses in a conditioning stimulation at $15 \mathrm{~Hz}$ and DA autoinhibition. Typical recordings show the DA overflow evoked by two test stimulations and one conditioning stimulation $(6$ pulses at $15 \mathrm{~Hz}$ ) in the striatum of one WT and one D2-/mouse $(A)$. Test stimulations (3 pulses at $100 \mathrm{~Hz}$ ) were applied $4 \mathrm{sec}$ before (S1) and $300 \mathrm{msec}$ after (S2) the end of Sc. The conditioning stimulation consisted of zero to six pulses at $15 \mathrm{~Hz}$. In WT mice, the maximal amplitude of the DA overflow evoked by Sc increased with increasing number of pulses from one to three and reached a plateau with the following pulses $(A)$. In contrast, in D2-/- mice, the DA overflow evoked by Sc never reached a plateau $(A)$. The DA overflow evoked by S2 was expressed in percentage of the overflow evoked by $\mathrm{S} 1(\mathbf{0}$; mean \pm SEM; 11 WT mice) $(B)$. In WT mice, the DA overflow evoked by Sc inhibited further DA release, and this inhibition increased by increasing Sc from two to five pulses $(B)$. In D2 $-/-$ mice, the DA overflow evoked by Sc (4 or 6 pulses) did not inhibit further DA release $(\bigcirc$; mean \pm SEM; $n=5)$.

DA are important parameters controlling the strength of autoreceptor stimulation. However, the duration of exposure contributed to this strength within a limited range. In fact, although stimulations consisting of three to six pulses at $15 \mathrm{~Hz}$ evoked DA overflow of increasing temporal summation (same maximal amplitude and increasing duration), the resulting autoinhibition reached a plateau with five and six pulses (Fig. $5 B$ ).

In WT mice, the DA overflow evoked by Sc either consisting of four or six pulses at $15 \mathrm{~Hz}$ reached a plateau after the third pulse (Figs. $4 B, 5 A$ ), whereas in D2-/- mice, this plateau was never observed when $\mathrm{Sc}$ consisted of four or six pulses at $15 \mathrm{~Hz}$ (Figs. $4 A, 5 A)$. Indeed, in WT mice, the DA overflow evoked by either four or six pulses had the same maximal amplitude (amplitude ratio, $0.98 \pm 0.04$; mean $\pm \mathrm{SEM}$; six animals), whereas in $\mathrm{D} 2-/-$ mice, the DA overflow evoked by six pulses was significantly larger $(p<0.05)$ than the overflow evoked by four pulses in the same animal (amplitude ratio, $1.18 \pm 0.05$; mean $\pm \mathrm{SEM} ; n=5$ ). This suggests that, in WT mice, the amount of DA released by the fourth pulse and those following was inhibited by early released DA during a train stimulation at $15 \mathrm{~Hz}$.

Autoinhibition induced by four pulses at $15 \mathrm{~Hz}$ vanished 600 msec after the end of the conditioning stimulation (Fig. 4). Are autoreceptors functional at this time? An experiment consisting 
A .
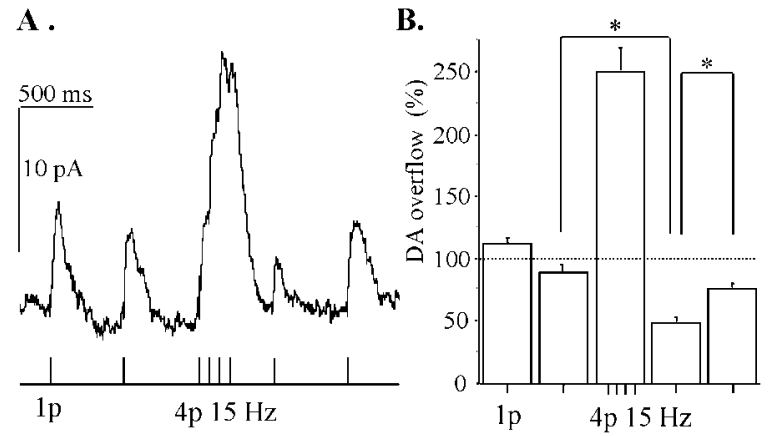

Figure 6. Inhibition of DA release with stimulations mimicking both discharge patterns of DA neurons. A typical recording in a WT mouse $(A)$ shows the DA overflow evoked by single pulses at $2 \mathrm{~Hz}$ before and after one stimulation of four pulses at $15 \mathrm{~Hz}$. The amplitude of the DA overflow observed for each stimulation is expressed in percentage (mean \pm SEM; $n=10$ ) of the averaged amplitudes of the DA overflow evoked by the two first single pulses $(B)$. A stimulation mimicking a burst (4 pulses at $15 \mathrm{~Hz}$ ) transiently inhibited further DA release evoked by single pulses mimicking the tonic discharge activity of dopaminergic neurons $\left({ }^{*} p=0.005\right)$.

of two steps was designed to address this question (data not shown). First, one conditioning stimulation consisting of four pulses at $15 \mathrm{HZ}$ inhibited DA release evoked by S2 (time interval of $200 \mathrm{msec}$ ). Second, two successive conditioning stimulations (four pulses at $15 \mathrm{~Hz}$ ) were applied with a time interval of 600 msec. DA autoinhibition induced by the latter was measured in the same way after a time interval of $200 \mathrm{msec}$. Both inhibitions were found similar (the DA overflow evoked by S2 expressed in percentage of the overflow evoked by S1 were $53.2 \pm 5.8$ and $56.4 \pm 5.1 \%$, respectively; mean $\pm \mathrm{SEM} ; n=9$ ), denoting complete recovery of autoinhibition function.

\section{Stimulations mimicking both discharge patterns of DA neurons}

Under physiological conditions, dopaminergic neurons tonically discharge in the single spike mode, and single bursts occur as an insert into this tonic activity (Grace and Bunney, 1984; Mirenowicz and Schultz, 1996; Horvitz et al., 1997). In rats and mice, the average discharge rate is 4-5 Hz (Grace and Bunney, 1984; Sanghera et al., 1984; Freeman and Bunney, 1987), and the percentage of spikes within bursts is $\sim 40 \%$ in freely moving rats (Freeman and Bunney, 1987). The stimulation protocol used in Figure 6 was designed to mimic a burst inserted into tonic activity.

Figure 6 shows that, with a $500 \mathrm{msec}$ interval, a single pulse stimulation only slightly inhibited the DA release evoked by the next single pulse. However, the DA overflow evoked by the bursting stimulation induced a marked inhibition of DA release evoked by the following single pulse stimulation. This inhibition was short lasting because the second single pulse, applied 800 msec after the burst, induced a DA overflow significantly higher than the overflow evoked by the previous one.

\section{DISCUSSION}

\section{In vivo versus in vitro studies}

The time course of DA autoinhibition in vivo represents our major observation. DA released in the extracellular space stimulates autoreceptors located on terminal fibers and inhibits its own further release for $600 \mathrm{msec}$. This duration is close to that described in vitro by Aroniadou-Anderjaska et al. (2000) for heteroregulation of glutamate release but shorter than durations observed in vitro regarding several other cases of presynaptic inhibition (Davies et al., 1990; Isaacson et al., 1993; Pfrieger et al., 1994; Mitchell and Silver, 2000), including DA autoinhibition (Limberger et al., 1991; Kennedy et al., 1992; Agneter et al., 1994). One difficulty encountered by these latter studies was that pharmacological blockade of autoreceptors did not completely block autoinhibition. Indeed, Kennedy et al. (1992) investigated the time course of autoinhibition of DA release by means of pairs of single pulse stimulations and observed a marked inhibition of the DA release evoked by the second pulse. However, this inhibition was only partly reversed by sulpiride. Similar observations have been reported by Mayer et al. (1988). The reasons for this failure have not been elucidated, but incomplete autoreceptor blockade has been suggested.

We observed here that DA autoinhibition was antagonized almost entirely by the mixed D1-D2 antagonist haloperidol. However, because haloperidol also altered DA clearance, we used another approach in control experiments revealing autoinhibition: we compared DA release in WT mice and in mice lacking D2 receptors, because autoreceptors are of the D2 type (SuaudChagny et al., 1991; Lhirondel et al., 1998). As expected, we found that DA autoinhibition was absent in D2-/- mice. Although both presynaptic and postsynaptic D2 receptors are lacking in these mice, only the former are involved in DA autoinhibition. Indeed, DA autoinhibition is still observed in the striatum of mice only lacking postsynaptic D2 receptors (Usiello et al., 2000).

\section{Mechanisms involved in the time course of DA autoinhibition}

With paired stimulations, we found that autoinhibition of DA release was already active, but not maximal, $100 \mathrm{msec}$ after the beginning of DA release. It is likely that DA autoreceptors are widely distributed outside synaptic contacts formed by dopaminergic terminals, because they can be stimulated by the extrasynaptic extracellular DA level (Suaud-Chagny et al., 1991). Therefore, diffusion of DA from release sites to autoreceptors might contribute to the kinetics of autoinhibition onset. However, estimates of DA diffusion in striatum suggests that this contribution is negligible. Indeed, synchronous DA release evoked by electrical stimulations might lead to homogenous DA concentration in the extrasynaptic extracellular space within $10 \mathrm{msec}$ (Garris et al., 1994; Gonon, 1997). Here, the evoked variations of DA concentration in the extrasynaptic extracellular space were directly monitored. Thus, we showed that DA autoinhibition is still maximal when DA released by the conditioning stimulation has been cleared from the extracellular space by reuptake. Therefore, both the onset and duration of autoinhibition are not governed by kinetics of the DA overflow bathing autoreceptors. This suggests that the time course of autoinhibition is governed by mechanisms downstream from autoreceptors, such as modulation of $\mathrm{Ca}^{2+}$ channels by G-proteins, as already shown regarding several autoregulations, including that of noradrenaline release mediated by $\alpha_{2}$ receptors (Hille, 1994; Herlitze et al., 1996; Koh and Hille, 1997; Wu and Saggau, 1997). Finally, at time intervals sufficiently long for complete recovery of DA release $(0.6 \mathrm{sec})$, we found that autoreceptors are fully able to activate again autoinhibition. Likewise, presynaptic metabotropic glutamate receptors inhibiting GABA release show no accommodation with prolonged stimulations (Mitchell and Silver, 2000). 


\section{Relationship between DA overflow and autoinhibition amplitude}

The DA overflow evoked in vivo by a single pulse induced little inhibition of further DA release, whereas repetitive stimulations were required to induce marked autoinhibition. In contrast, in vitro studies showed marked DA autoinhibition elicited by single pulses (Limberger et al., 1991; Kennedy et al., 1992). This discrepancy between in vivo and in vitro observations might be related to the fact that "for reasons which are not clear, local electrical stimulation of dopamine release in slices leads to abnormally high extracellular concentration, relative to equivalent stimulations in vivo using remote locations" (Michael and Wightman, 1999) (see also Kennedy et al., 1992; M. Benoit-Marand, unpublished observations). Although autoinhibition of GABA release can be elicited in slices by a single pulse (Davies et al., 1990), bursts of four pulses are more effective (Cobb et al., 1999). Repetitive stimulations are also required to elicit presynaptic inhibition mediated by $\mathrm{GABA}_{\mathrm{B}}$ and metabotropic glutamate receptors in slices of hippocampus and cerebellum (Isaacson et al., 1993; Scanziani et al., 1997; Mitchell and Silver, 2000).

Repetitive stimulation is thought to promote neurotransmitter spillover outside the synaptic cleft and, thus, activation of extrasynaptic G-protein-coupled receptors (Hille, 1992; Isaacson et al., 1993; Scanziani et al., 1997; Mitchell and Silver, 2000). Regarding DA, it has been shown in vivo that most of DA released by a single pulse diff uses outside synaptic cleft before reuptake (Garris et al., 1994; Gonon, 1997). However, as illustrated here, repetitive stimulation mimicking physiological bursts actually promotes DA accumulation in the extrasynaptic extracellular space mainly by overcoming DA reuptake (Chergui et al., 1994). We found that such accumulation is needed to induce marked activation of D2 autoreceptors.

The relationship between the DA overflow evoked by repetitive stimulations and autoinhibition amplitude appears complex: the maximal extracellular DA level and the duration of DA exposure both contribute to the strength of autoreceptor stimulation. Similar observations have already been reported regarding stimulation of postsynaptic D1 receptors (Gonon, 1997). Both studies support Hille's hypothesis of a "temporal summation" at G-protein-coupled receptors (Hille, 1992).

\section{Physiological functions of DA autoinhibition}

Under physiological conditions, the extracellular DA concentration is almost entirely related to impulse flow (Keefe et al., 1993; Svenningsson et al., 1999). Dopaminergic neurons tonically discharge at low frequency and respond by one burst to sensory (Steinfels et al., 1983; Freeman and Bunney, 1987; Horvitz et al., 1997) and appetitive stimuli (Mirenowicz and Schultz, 1996). The role played by DA autoinhibition in the relationship between impulse flow and DA release is discussed below in light of our observations concerning synchronous DA release evoked by exogenous impulse flow triggered by MFB electrical stimulation. The artificial nature of our study must be kept in mind when considering the following interpretations.

Our data concerning DA overflow evoked by single pulses strongly suggest that autoinhibition plays a minor role in regulating DA release during tonic single spike activity. Concerning DA overflow evoked by one burst, the role of autoinhibition depends on burst length. The number of spikes per burst averages 3.2, but bursts of up to 20 spikes are occasionally observed (Freeman et al., 1985). We observed here that blockade of D2 autoreceptors by haloperidol heterogenously enhanced the DA overflow evoked by train stimulations consisting of six pulses at $15 \mathrm{~Hz}$ : it minimally affected the early phase of the DA overflow corresponding to first pulses but greatly enhanced its late phase. Similar observations have been reported regarding the effects of D2 antagonists on DA overflow evoked by more prolonged stimulations (Kennedy et al., 1992; Dugast et al., 1994; Garris et al., 1994; Cragg and Greenfield, 1997). These observations suggest that, via autoreceptors, DA released by the first pulses inhibits further DA release evoked by the following pulses in a train. However, these data are difficult to analyze. Indeed, because DA overflow results from DA release minus DA clearance by reuptake, DA overflow evoked by train stimulations at physiological frequency $(\leq 20 \mathrm{~Hz})$ reaches a plateau after few pulses because of an equilibrium between release and uptake (Dugast et al., 1994; Garris et al., 1994). Because D2 antagonists also indirectly inhibit DA uptake (Cass and Gerhardt, 1994), the specific role of autoinhibition is not clearly shown with these antagonists. However, comparison shown here between WT and D2 $-/-$ mice further suggests that, together with DA uptake, autoinhibition actually prevents excessive extracellular DA by imposing a plateau to DA overflow evoked by bursts consisting of four pulses or more.

Repetitive bursting occurs at a frequency below $1 \mathrm{~Hz}$ (Grace and Bunney, 1984; Freeman et al., 1985). We show here that single bursts induce a marked inhibition of further DA release lasting for $0.6 \mathrm{sec}$. Therefore, in physiological conditions, most successive bursts do not inhibit each other. After one burst elicited by appetitive stimuli, the tonic activity is still present without apparent alteration (Mirenowicz and Schultz, 1996), whereas after sensory stimuli it tends to decrease (Steinfels et al., 1983; Horvitz et al., 1997). Freeman et al. (1985) reported a postburst inhibitory period of $320 \mathrm{msec}$ in freely moving rats. Therefore, via autoinhibition, single bursts are in a position to phasically inhibit for $0.6 \mathrm{sec}$ additional DA release induced by tonic activity.

The role played by DA autoinhibition on DA transmission mediated by postsynaptic dopaminergic receptors is discussed below in the light of hypotheses proposed by Gerfen and Wilson (1996), although it must be recognized that the postsynaptic action of dopamine on D1 receptors is probably more complex than suggested by these hypotheses (Calabresi et al., 1997). In dorsal striatum, $95 \%$ of the neuronal cell bodies belong to two populations: striatopallidal and striatonigral neurons (Gerfen and Wilson, 1996). The basal extracellular DA level caused by tonic activity is high enough to tonically inhibit gene expression specifically in striatopallidal neurons, and this effect is mediated by postsynaptic D2 receptors (Gerfen and Wilson, 1996; Svenningsson et al., 1999). In contrast, a higher extracellular DA level induced by either psychostimulants (Johansson et al., 1994; Gerfen and Wilson, 1996) or burst stimulation (Chergui et al., 1997) is required to specifically increase gene expressions in striatonigral neurons via D1 receptors. Moreover, the DA overflow evoked by bursts facilitates in vivo the discharge activity of a subpopulation of striatal neurons via D1 receptors (Gonon, 1997). Autoinhibition might play two important roles on DA transmission. First, during bursts of action potentials, it prevents excessive extracellular DA. Therefore, it contributes, together with DA uptake, to shape the presynaptic signal controlling DA transmission mediated by D1 receptors. Second, the DA overflow evoked by one burst triggers a delayed and prolonged inhibition of further DA release and, thus, might transiently attenuate the tonic inhibitory DA transmission mediated by D2 postsynaptic receptors. 


\section{REFERENCES}

Agneter E, Hoffmann IS, Singer EA, Cubeddu LX (1994) Behavior of mesocortical dopamine terminals during single and repetitive stimulation: comparison with nigrostriatal neurons. J Pharmacol Exp Ther 269:470-476.

Aroniadou-Anderjaska V, Zhou FM, Priest CA, Ennis M, Shipley MT (2000) Tonic and synaptically evoked presynaptic inhibition of sensory input to the rat olfactory bulb via GABA(B) heteroreceptors. J Neurophysiol 84:1194-1203.

Baik JH, Picetti R, Saiardi A, Thiriet G, Dierich A, Depaulis A, Le Meur M, Borrelli E (1995) Parkinsonian-like locomotor impairment in mice lacking dopamine D2 receptors. Nature 377:424-428.

Benoit-Marand M, Jaber M, Gonon F (2000) Release and elimination of dopamine in vivo in mice lacking the dopamine transporter: functional consequences. Eur J Neurosci 12:2985-2992.

Calabresi P, Pisani A, Centonze D, Bernardi G (1997) Synaptic plasticity and physiological interactions between dopamine and glutamate in the striatum. Neurosci Biobehav Rev 21:519-523.

Cass WA, Gerhardt GA (1994) Direct in vivo evidence that D2 dopamine receptors can modulate dopamine uptake. Neurosci Lett $176: 259-263$

Chergui K, Suaud-Chagny MF, Gonon F (1994) Nonlinear relationship between impulse flow, dopamine release and dopamine elimination in the rat brain in vivo. Neuroscience 62:641-645.

Chergui K, Svenningsson P, Nomikos G, Gonon F, Fredholm BB, Svensson TH (1997) Increased expression of NGFI-A mRNA in the rat striatum following burst stimulation of the medial forebrain bundle. Eur J Neurosci 9:2370-2382.

Cobb SR, Manuel NA, Morton RA, Gill CH, Collingridge GL, Davies $\mathrm{CH}$ (1999) Regulation of depolarizing $\mathrm{GABA}_{\mathrm{A}}$ receptor-mediated synaptic potentials by synaptic activation of $\mathrm{GABA}_{\mathrm{B}}$ autoreceptors in the rat hippocampus. Neuropharmacology 38:1723-1732.

Cragg SJ, Greenfield SA (1997) Differential autoreceptor control of somatodendritic and axon terminal dopamine release in substantia nigra, ventral tegmental area, and striatum. J Neurosci 17:5738-5746.

Davies CH, Davies SN, Collingridge GL (1990) Paired-pulse depression of monosynaptic GABA-mediated inhibitory postsynaptic responses in rat hippocampus. J Physiol (Lond) 424:513-531.

Dickinson SD, Sabeti J, Larson GA, Giardina K, Rubinstein M, Kelly MA, Grandy DK, Low MJ, Gerhardt GA, Zahniser NR (1999) Dopamine D-2 receptor-deficient mice exhibit decreased dopamine transporter function but no changes in dopamine release in dorsal striatum. J Neurochem 72:148-156.

Dugast C, Suaud-Chagny MF, Gonon F (1994) Continuous in vivo monitoring of evoked dopamine release in the rat nucleus accumbens by amperometry. Neuroscience 62:647-654.

Dugast C, Brun P, Sotty F, Renaud B, Suaud-Chagny MF (1997) On the involvement of a tonic dopamine D2-autoinhibition in the regulation of pulse-to-pulse-evoked dopamine release in the rat striatum in vivo. Naunyn Schmiedebergs Arch Pharmacol 355:716-719.

Franklin KBJ, Paxinos G (1997) The mouse brain in stereotaxic coordinates. San Diego: Academic.

Freeman AS, Bunney BS (1987) Activity of A9 and A10 dopaminergic neurons in unrestrained rats: further characterization and effects of apomorphine and cholecystokinin. Brain Res 405:46-55.

Freeman AS, Meltzer LT, Bunney BS (1985) Firing properties of substantia nigra dopaminergic neurons in freely moving rats. Life Sci 36:1983-1994.

Garris PA, Ciolkowski EL, Pastore P, Wightman RM (1994) Efflux of dopamine from the synaptic cleft in the nucleus accumbens of the rat brain. J Neurosci 14:6084-6093.

Gerfen CR, Wilson CJ (1996) The basal ganglia. In: Handbook of chemical neuroanatomy, integrated systems of the CNS, Vol 12, Pt III (Swanson LW, Björklund A, Hökfelt T, eds), pp 371-468. Amsterdam: Elsevier.

Gonon F (1997) Prolonged and extrasynaptic excitatory action of dopamine mediated by $\mathrm{D} 1$ receptors in the rat striatum in vivo. $\mathrm{J}$ Neurosci 17:5972-5978.

Grace AA, Bunney BS (1984) The control of firing pattern in nigral dopamine neurons: burst firing. J Neurosci 4:2877-2890.

Herlitze S, Garcia DE, Mackie K, Hille B, Scheuer T, Catterall WA (1996) Modulation of $\mathrm{Ca}^{2+}$ channels by G-protein $\beta \gamma$ subunits. Nature 380:258-262.

Hille B (1992) G-protein-coupled mechanisms and nervous signaling. Neuron 9:187-195.
Hille B (1994) Modulation of ion-channel function by G-protein-coupled receptors. Trends Neurosci 17:531-536.

Horvitz JC, Stewart T, Jacobs BL (1997) Burst activity of ventral tegmental dopamine neurons is elicited by sensory stimuli in the awake cat. Brain Res 759:251-258.

Isaacson JS, Solis JM, Nicoll RA (1993) Local and diffuse synaptic actions of GABA in the hippocampus. Neuron 10:165-175.

Johansson B, Lindström K. Fredholm BB (1994) Differences in the regional and cellular localization of $c$-fos messenger RNA induced by amphetamine, cocaine and caffeine in the rat. Neuroscience 59:837-849.

Keefe KA, Sved AF, Zigmond MJ, Abercrombie ED (1993) Stressinduced dopamine release in the neostriatum: evaluation of the role of action potentials in nigrostriatal dopamine neurons or local initiation by endogenous excitatory amino acids. J Neurochem 61:1943-1952.

Kelly MA, Rubinstein M, Phillips TJ, Lessov CN, BurkhartKasch S Zhang G, Bunzow JR, Fang Y, Gerhardt GA, Grandy DK, Low MJ (1998) Locomotor activity in D2 dopamine receptor-deficient mice is determined by gene dosage, genetic background, and developmental adaptations. J Neurosci 18:3470-3479.

Kennedy RT, Jones SR, Wightman RM (1992) Dynamic observation of dopamine autoreceptor effects in rat striatal slices. J Neurochem 59:449-455

Koh DS, Hille B (1997) Modulation by neurotransmitters of catecholamine secretion from sympathetic ganglion neurons detected by amperometry. Proc Natl Acad Sci USA 94:1506-1511.

Lhirondel M, Cheramy A, Godeheu G, Artaud F, Saiardi A, Borrelli E, Glowinski J (1998) Lack of autoreceptor-mediated inhibitory contro of dopamine release in striatal synaptosomes of D2 receptor-deficient mice. Brain Res 792:253-262.

Limberger N, Trout SJ, Kruk ZL, Starke K (1991) Real time measurement of endogenous dopamine release during short trains of pulses in slices of rat neostriatum and nucleus accumbens: role of autoinhibition. Naunyn Schmiedebergs Arch Pharmacol 344:623-629.

Mayer A, Limberger N, Starke K (1988) Transmitter release patterns of noradrenergic, dopaminergic and cholinergic axons in rabbit brain slices during short pulse trains, and the operation of presynaptic autoreceptors. Naunyn Schmiedebergs Arch Pharmacol 338:632-643.

Michael DJ, Wightman RM (1999) Electrochemical monitoring of biogenic amine neurotransmission in real time. J Pharm Biomed Anal 19:33-46.

Mirenowicz J, Schultz W (1996) Preferential activation of midbrain dopamine neurons by appetitive rather than aversive stimuli. Nature 379:449-451.

Mitchell SJ, Silver RA (2000) Glutamate spillover suppresses inhibition by activating presynaptic mGluRs. Nature 404:498-502.

Nicoll RA, Malenka RM, Kauer JA (1990) Functional comparison of neurotransmitter receptor subtypes in mammalian central nervous system. Physiol Rev 70:513-565.

Pfrieger FW, Gottmann K, Lux HD (1994) Kinetics of GABAB receptor-mediated inhibition of calcium currents and excitatory synaptic transmission in hippocampal neurons in vitro. Neuron 12:97-107.

Sanghera MK, Trulson ME, German DC (1984) Electrophysiological properties of mouse dopamine neurons: in vivo and in vitro studies. Neuroscience 12:793-801.

Scanziani M, Salin PA, Vogt KE, Malenka RC, Nicoll RA (1997) Usedependent increases in glutamate concentration activate presynaptic metabotropic glutamate receptors. Nature 385:630-634.

Starke K, Gother M, Kilbinger H (1989) Modulation of neurotransmitter release by presynaptic autoreceptors. Physiol Rev 69:864-989.

Steinfels GF, Heym J, Strecker RE, Jacobs BL (1983) Behavioral correlates of dopaminergic unit activity in freely moving cats. Brain Res 258:217-228

Suaud-Chagny MF, Ponec J, Gonon F (1991) Presynaptic autoinhibition of the electrically evoked dopamine release studied in the rat olfactory tubercle by in vivo electrochemistry. Neuroscience 45:641-652.

Svenningsson P, Fourreau L, Bloch B, Fredholm BB, Gonon F, Le Moine C (1999) Opposite tonic modulation by dopamine and adenosine on c-fos expression in the striatopallidal neurons. Neuroscience 89:827-837.

Thompson SM, Capogna M, Scanziani M (1993) Presynaptic inhibition in the hippocampus. Trends Neurosci 16:222-227.

Usiello A, Baik JH, Rouge-Pont F, Picetti R, Dierich A, LeMeur M, Piazza PV, Borrelli E (2000) Distinct functions of the two isoforms of dopamine D2 receptors. Nature 408:199-203.

Wu LG, Saggau P (1997) Presynaptic inhibition of elicited neurotransmitter release. Trends Neurosci 20:204-212. 